\title{
A proposed framework for sustainable international partnerships: lessons learned in rural Uganda
}

\author{
Carol C Chen', Andrea T Cruz², Heather Honoré Goltz ${ }^{3}$, Esther M Sampayo ${ }^{2}$ \\ 1 Division of Pediatric Emergency Medicine, Department of Emergency Medicine, University of California at San Francisco, San Francisco, California, \\ USA, ${ }^{2}$ Division of Emergency Medicine, Department of Pediatrics, Baylor College of Medicine, Houston, Texas, USA, 3 Social Work Program, University \\ of Houston-Downtown, Texas, USA \\ Keywords: global health \\ https://doi.org/10.29392/joghr.3.e2019054
}

\section{Journal of Global Health Reports}

Vol. 3, 2019

\begin{abstract}
Background
International non-governmental organizations (NGOs) have widespread experience building health-related programs; however, few studies have examined local stakeholder perceptions of their collaboration and sustainability.
\end{abstract}

\section{Objective}

To describe attitudes and beliefs of five stakeholder groups concerning the building of a healthcare facility in rural Uganda by an international NGO, with the goal of developing a potential framework.

\section{Methods}

A qualitative study was conducted using focus groups, semi-structured interviews, and open-ended questionnaires. The five participating stakeholder groups included: community members, community leaders, healthcare workers, NGO leaders, and representatives from the Ugandan Ministry of Health.

\section{Results}

All 40 participants reported interest in working together and four principal themes were identified: crucial building blocks of a healthcare facility; expectations regarding collaborative relationships; key deliverables desired by the community; and specific obstacles to sustainability.

\section{Conclusions}

Participating stakeholders believe that the most important components of sustainable healthcare facilities are the establishment of two-way partnerships within the community and an emphasis on deliverables such as education, higher standards of care, and maintainable infrastructure. Unique obstacles must also be recognized. We propose a conceptual framework that may be applied to future public health interventions in resource-limited, international settings.

Numerous international non-governmental organizations (NGOs) focus on improving community health in the low resource settings. Examples of initiatives include health education programs and construction and operation of health facilities. ${ }^{1-4}$ Their strategies are as heterogeneous as their results. While multiple models of "sustainable partnerships" have been published, there is a paucity of literature on how critical components interact in successful and sustainable interventions in resource-limited settings. ${ }^{5-7}$

One such model is the Community Driven Development model (CDD), which posits that individual communities are responsible for initiating, implementing, and sustaining their own projects - apparently producing truly community-driven efforts, however its success can be variable. ${ }^{8-14}$
The effort described here is similar in that it was born of a community-identified need and -led effort, but it goes a step further by examining community beliefs and perceptions on collaboration and success. There has been limited published work in this area thus far. ${ }^{15}$

Recognizing that collaborations rely on complex networks of relationships between different stakeholders, this study describes the attitudes and experiences of five groups of key stakeholders regarding the development and construction of a sustainable health center by an NGO in their rural Ugandan community of approximately 5000 people. The local NGO has worked in this community since 2007, during which time the first author conducted the needs assessment that shaped the plans for the center. By explor- 


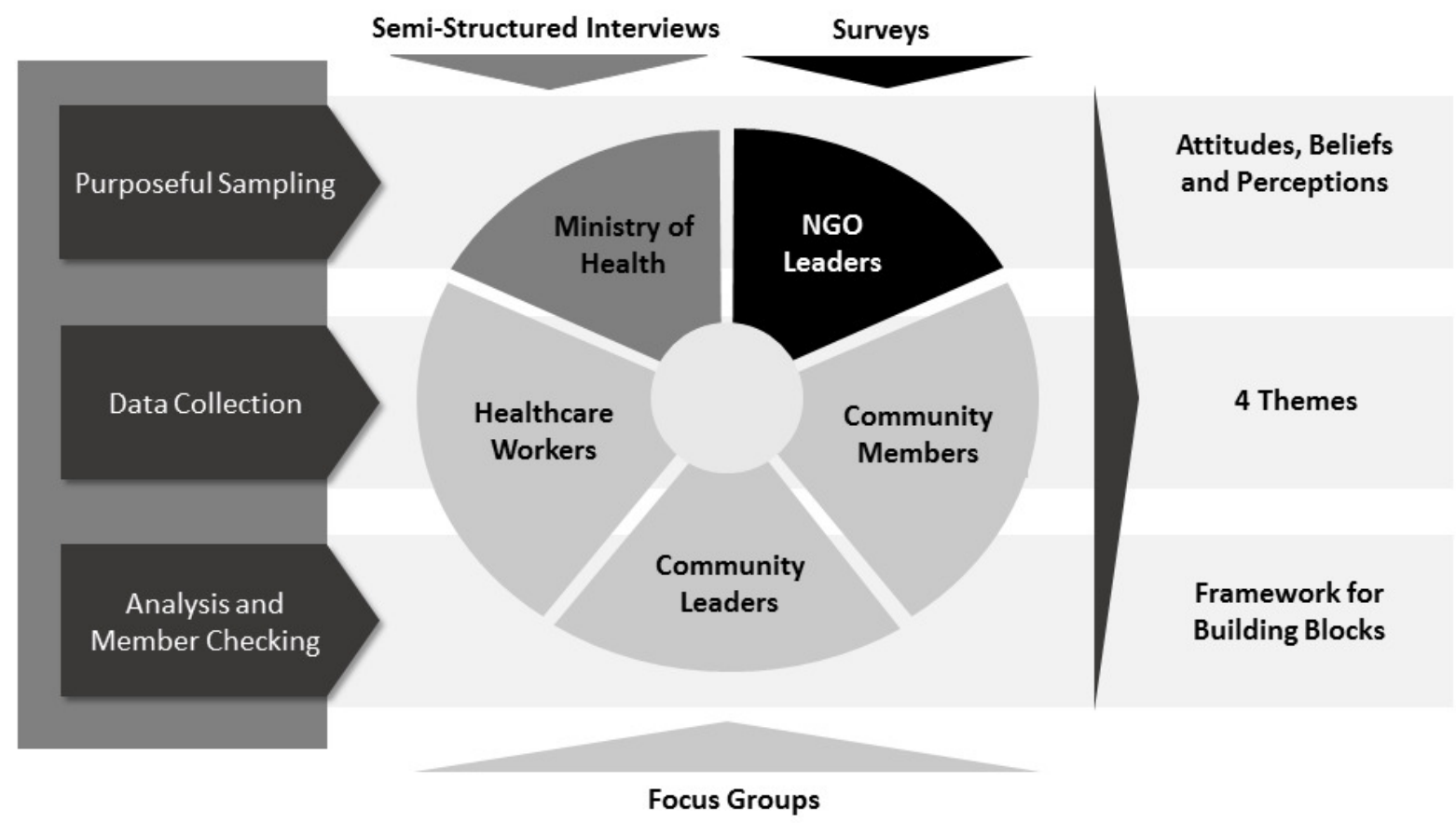

Figure 1. Study design for sustainable partnerships qualitative study.

NGO - non-governmental organization.

ing critical components and how they interact in constructing sustainable partnerships using "grounded theory", we attempted to develop a potential framework for the most important building blocks in such interventions. This could inform ongoing and future efforts by agencies working in similar sites.

\section{METHODS}

\section{STUDY DESIGN}

This qualitative study consisted of semi-structured, openended focus groups and individual interviews, and openended questionnaires obtained from a purposive sample of members of five pre-defined stakeholder groups. These groups were developed a priori during a needs assessment and consisted of persons whose collaboration was crucial to the successful construction and operation of the proposed health center (Figure 1).

Using qualitative analyses we explored stakeholders' attitudes, beliefs and perceptions regarding the development of the health center in their community by an international NGO. Researchers used "triangulation”, or the use of multiple methods for collecting data to enhance comprehension of complex topics, ${ }^{16}$ to integrate data from interviews, focus groups, and questionnaires into the analysis. Demographic data was entered into a database (Excel; Microsoft Corp, Redmond, WA) and descriptive statistics summarized stakeholder characteristics.

The study protocol and consent procedures were approved by the Uganda National Council for Science and Technology and Baylor College of Medicine Institutional Review Board. All participants provided informed consent verbally with interpreters available if needed.

\section{PARTICIPANTS}

Participants were members of the stakeholder groups: community members ${ }^{1}$; community leaders ${ }^{2}$; healthcare workers $^{3}$; local representatives of the Ugandan Ministry of Health $(\mathrm{MoH})^{4}$; and leaders of local NGOs. ${ }^{5}$ All were 18 years or older and represented the community served by the proposed health center. Researchers identified potential participants using the snowball technique, whereby one stakeholder group member subsequently identified another group member to participate in the study. ${ }^{17}$

\section{INTERVIEWS, FOCUS GROUPS, AND QUESTIONNAIRES}

A detailed guide for all focus groups and interviews was developed, pilot-tested and revised during several research team meetings (Appendix S1 in the Online Supplementary Document). The same interviewer (CCC) was trained in interviewing techniques prior to completing all interviews and focus groups. Study team members communicated weekly throughout the data collection period to discuss study progress, recruitment, and any quality control issues.

The intrinsic nature of each stakeholder group dictated the method by which data was collected and provided "triangulation."16 (Figure 1). Three stakeholder groups (i.e., community members, community leaders, and healthcare workers) represented a large and diverse constituency; therefore, focus groups were deemed ideal for the collection of data. Due to small numbers of MoH group members, interviews were conducted instead of focus groups.

After permission was obtained from participants, all focus groups and interviews were digitally recorded, transcribed and coded by investigators and staff trained in issues of confidentiality. These sessions were conducted in 
a private office setting in English with the assistance of a local interpreter. Transcription was performed by a professional service for the English portions of the audio recordings only (The Lighthouse of Houston; Houston, TX). Each interaction consisted of a close-ended assessment of participants' interest in cooperating with other groups on the development of the health center, as ranked on a scale of $0-10$ ( 0 representing no interest and 10 indicating the highest level of interest), and open-ended questions from the guide.

Leaders of local NGOs were geographically dispersed, but had consistent access to internet service. Therefore, questionnaires were distributed directly and via email, then returned by mail or electronically.

\section{ANALYSIS}

Researchers (CCC, EMS) used "constant comparison" analysis, whereby they repeatedly read through transcripts and written responses to questionnaires, formulated an initial framework of key codes, and refined these codes with successive readings. They developed mutually agreed-upon definitions and examples for each code. Codes were reviewed and revised with disagreements in coding resolved by team consensus. The same two members met to discuss findings and develop themes from the codes. Memos of coding decisions were kept to provide consistency in coding as analysis progressed.

The "thematic approach", a widely utilized process in the analysis of qualitative data, was used to identify a conceptual framework of themes corresponding to stakeholders' attitudes, beliefs, and perceptions concerning important components to consider in the planning and construction of a sustainable healthcare facility in rural Uganda. ${ }^{16,18}$ Content "saturation" was achieved when no new themes emerged in successive focus group or interview transcripts. 19

"Member checking” via 3 focus groups and 2 interviews with participants from similar groups was performed 8 months after the initial data collection period to check for accuracy and completeness of the findings. ${ }^{20}$ This data was not included in the current analysis.

\section{RESULTS}

There were 40 total participants; demographic data were collected for 37 (93\%; Table 1). All data were collected in Uganda during a 7-month period in 2013. There were 17 participants in the community member group, 9 in the community leader group, and 10 in the healthcare worker group. Two individuals were interviewed for $\mathrm{MoH}$ and 2 of 3 questionnaires were returned from NGO leaders. Ten community members, 5 community leaders, 4 healthcare workers, $1 \mathrm{MoH}$ worker, and $2 \mathrm{NGO}$ leaders participated in memberchecking.

There were 2 focus group sessions with each stakeholder group. All participants across all stakeholder groups ranked their interest in collaborating with other groups as "10," or "most interested."

Four major themes emerged from these data (Table 2). First, infrastructure, financial support, medical supplies and trained personnel were recognized as crucial building blocks of the proposed healthcare facility. Next, relationships among stakeholders were emphasized. Participants identified the need to foster community trust, respect, cooperation and confidentiality to sustain strong affiliations. Third, the community described key deliverables they desired, such as health education and higher standards for quality health care delivery. Finally, obstacles to the building process were identified as corruption, entitlement in the setting of scarce employment opportunities, lack of cultural awareness, and shortage of skilled personnel. These findings identify a potential conceptual framework of the most important components needed to build a sustainable partnership in a resource-limited setting (Figure 2).

Across all stakeholder groups, the most commonly identified themes were the importance of building blocks and deliverables. For community leaders, $\mathrm{MoH}$, and NGO leaders, the importance of relationships and the need for partnership was stressed as one of the most significant drivers of sustainability.

\section{INTERVIEW THEMES}

\section{BUILDING BLOCKS}

Four of the 5 stakeholder groups identified infrastructure and financial considerations as crucial building blocks of a healthcare facility. Infrastructure encompassed such factors as proximity of the center, laboratory facilities, medication availability, an effective triage system, and an affordable ambulance service. Financial considerations included the current cost of healthcare services, the impact of costs on health care choices, and a proposed cost-sharing system. Most participants believed that the ideal payment scheme should include reduced fees for services funded by donor subsidies.

Although participants shared stories of how medical services were not obtained due to insufficient funds, there were also remarks highlighting the lack of medical supplies in the setting of affordability.

“... hospitals would be good if... drugs would be there
but most of the times you find that drugs are finished.
People are going every week, two weeks... how can
somebody survive without drugs for two weeks? That's
why we are getting a lot of mortality in the hospitals."
(Community Member)

\section{RELATIONSHIPS}

Three stakeholder groups with intrinsic leadership roles (community leaders, MoH and NGO leaders) stressed the importance of relationships in the health center's developmental process. While all of the stakeholder groups expressed a strong interest in cooperating, community leaders and $\mathrm{MoH}$ emphasized the importance of frequent, open communication, cooperation and confidentiality, as well as the need for a two-way partnership. Emphasis was also placed on the community's trust in established organizations. In regards to building the health center, participants were "grateful" and viewed the "new hospital nearby" as a "great change for this community." Many participants also 
Table 1. Descriptive statistics of 37 participants

\begin{tabular}{lll}
\hline Descriptor & Response categories & Number (\%) \\
\hline Age (years) & Mean, range & $39.7,20-64$ \\
Gender & Female & $23(62 \%)$ \\
Marital status & Married & $26(70 \%)$ \\
& Single & $7(19 \%)$ \\
& Widow & $3(8 \%)$ \\
Highest level of education attained & Divorced & $1(3 \%)$ \\
& Primary & $14(38 \%)$ \\
& Secondary & $12(32 \%)$ \\
& Diploma & $5(13.5 \%)$ \\
& University & $4(11 \%)$ \\
\end{tabular}

Table 2. Themes developed from the most common codes, organized by stakeholder group

\begin{tabular}{|c|c|c|c|c|c|}
\hline & $\begin{array}{l}\text { Healthcare } \\
\text { Workers, } \\
10 \text { participants }\end{array}$ & $\begin{array}{l}\text { Community } \\
\text { Members, } \\
17 \text { participants }\end{array}$ & $\begin{array}{l}\text { Community } \\
\text { Leaders, } \\
9 \text { participants }\end{array}$ & $\begin{array}{l}\text { Ministry of } \\
\text { Health, } \\
2 \text { participants }\end{array}$ & $\begin{array}{l}\text { NGO Leaders, } \\
2 \text { participants }\end{array}$ \\
\hline \multirow[t]{2}{*}{ Building Blocks } & Infrastructure & Infrastructure & $\begin{array}{l}\text { Financial } \\
\text { considerations }\end{array}$ & $\begin{array}{l}\text { Financial } \\
\text { considerations }\end{array}$ & \\
\hline & $\begin{array}{l}\text { Financial } \\
\text { considerations }\end{array}$ & $\begin{array}{l}\text { Financial } \\
\text { considerations }\end{array}$ & Infrastructure & Infrastructure & \\
\hline \multirow[t]{4}{*}{ Deliverables } & $\begin{array}{l}\text { Quality/standard of } \\
\text { care }\end{array}$ & $\begin{array}{l}\text { Employment } \\
\text { opportunities }\end{array}$ & Infrastructure & Infrastructure & $\begin{array}{l}\text { Education/ } \\
\text { research }\end{array}$ \\
\hline & $\begin{array}{l}\text { Community health } \\
\text { needs }\end{array}$ & $\begin{array}{l}\text { Quality/ } \\
\text { standard of care }\end{array}$ & $\begin{array}{l}\text { Employment } \\
\text { opportunities }\end{array}$ & $\begin{array}{l}\text { Education/ } \\
\text { research }\end{array}$ & $\begin{array}{l}\text { Community } \\
\text { health needs }\end{array}$ \\
\hline & Education/ research & $\begin{array}{l}\text { Community } \\
\text { health needs }\end{array}$ & $\begin{array}{l}\text { Quality/ } \\
\text { standard of } \\
\text { care }\end{array}$ & $\begin{array}{l}\text { Community } \\
\text { health needs }\end{array}$ & Sustainability \\
\hline & Infrastructure & $\begin{array}{l}\text { Education/ } \\
\text { research }\end{array}$ & $\begin{array}{l}\text { Community } \\
\text { health needs }\end{array}$ & Infrastructure & \\
\hline \multirow[t]{2}{*}{ Relationships } & Trust & $\begin{array}{l}\text { Religious and } \\
\text { local traditions }\end{array}$ & $\begin{array}{l}\text { Interest in } \\
\text { cooperating }\end{array}$ & $\begin{array}{l}\text { Open } \\
\text { communication }\end{array}$ & $\begin{array}{l}\text { Community } \\
\text { development }\end{array}$ \\
\hline & Confidentiality & $\begin{array}{l}\text { Interest in } \\
\text { cooperating }\end{array}$ & $\begin{array}{l}\text { Community } \\
\text { trust }\end{array}$ & & \\
\hline \multirow[t]{2}{*}{ Obstacles } & Entitlement & Proximity & Corruption & $\begin{array}{l}\text { Shortage of } \\
\text { skilled personnel }\end{array}$ & $\begin{array}{l}\text { Sense of } \\
\text { helplessness }\end{array}$ \\
\hline & $\begin{array}{l}\text { Scarce employment } \\
\text { opportunities }\end{array}$ & & & & \\
\hline
\end{tabular}

NGO - non-governmental organizations

underscored the importance of recognizing religious and local traditions as a way of building partnerships.

\section{DELIVERABLES}

All stakeholder groups identified specific deliverables from the proposed health center as important considerations, such health care delivery and employment, when planning the facility. They highlighted the need for health education for the community, which is scarce in the region. They stressed the need for quality health care delivered by welltrained, well-compensated healthcare workers. "Quality health care" encompassed not only the services delivered but the availability of supplies, sanitary practices, and tech- nology. A local MoH representative discussed the quality of care delivered by most NGOs in Uganda:

"Honestly, what I like about you NGOs is they're real result-oriented. ... you really see them focusing a lot on results and they tend to do quality work... most of them have very standard infrastructure. ...Our patients, they're really in safe hands."

Several healthcare workers cited examples of poor hygiene practices in public facilities, and multiple community members criticized the bedside manner of nurses, saying “... they mistreat patients. They don't talk well with patients.” Another commented: 


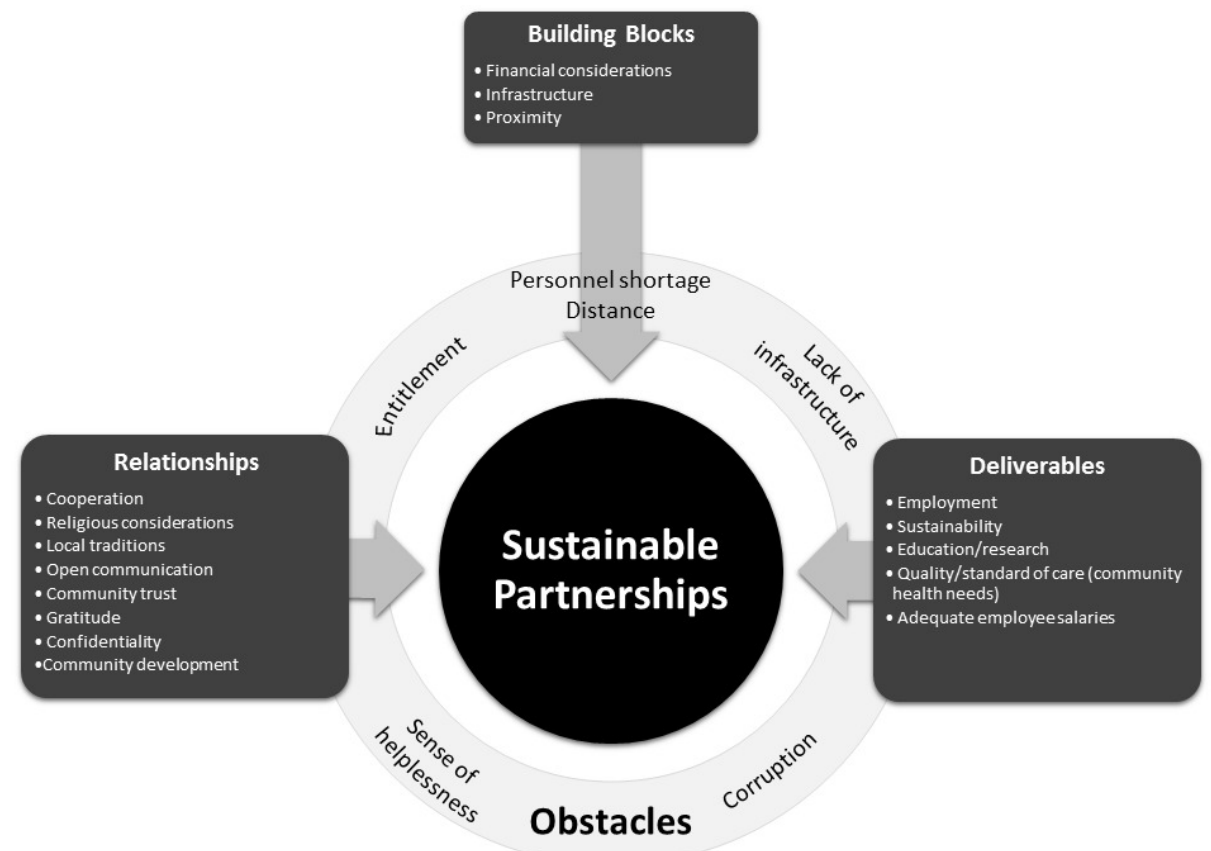

Figure 2. Conceptual framework for the most important components needed to build a sustainable partnership in a healthcare facility.

\begin{abstract}
“...If you choose workers that are going to work in the hospital, choose people who will be respecting ... knowing that people's words have meaning... You don't need people who don't feel passion, emotion..." (Community member)
\end{abstract}

The importance of education and research were emphasized, both for potential patients and for existing healthcare workers. Among community members, where an overall HIV prevalence of $20 \%$ exists, education emerged as an important topic when discussing HIV awareness and destigmatization. Members within the 3 groups holding intrinsic leadership positions in the community expressed some wariness in regards to medical research and its potential role within the health center. A community leader commented:

\footnotetext{
"Research is good. It has done us good but... there is a way it worries our people ...Now somebody- will not focus on getting a solution done but instead he's going to worry. He's not having enough funds; ... they're not actually caring for them."
}

In addition, $\mathrm{MoH}$ participants highlighted the importance of sustainability:

“... maybe what I don't like about them (NGOs) sometimes - some of them set unrealistic targets on standards which you cannot sustain after they've pulled out, eh? ...so sustainability is a bit of a challenge... if you're coming aboard we need to bear in mind an issue of sustainability because at one time or another it will come (to an) end."

\section{OBSTACLES}

The roles of obstacles in building a sustainable health care center were expressed in every stakeholder group. Proximity was cited as a barrier to healthcare as more advanced medical care was only available in a close, but expensive private facility, or in a public hospital that required lengthy travel. A shortage of trained healthcare personnel was also identified as an obstacle to the development of the facility.

One element of corruption that was commonly reported was the practice of charging fees for health services that are intended to be offered for free (via government subsidies) in public facilities. A community member commented:

" “... those doctors and nurses who work in government hospitals... like you are going to deliver (a baby) they charge you money yet the government is paying them salaries - they are working on you privately yet the government is the one paying..."

More unique obstacles were specifically presented by NGO leaders, who expressed a sense of being overwhelmed.

"There are many years of cultural issues and beliefs that are embedded deeply and it sometimes feels overwhelming to think they will ever be changed."

Many groups also expressed feelings of gratitude and community trust towards NGOs working in their communities.

“... when the NGOs come around they create employment for our people. So people are able to live a comfortable life because...they are well employed, they're earning a good salary.” (MoH). 
However, there was also a sense of entitlement. Several local community members and healthcare workers declared their "rights" to any employment opportunities that might be created by the proposed health center. A nurse stated:

$$
\begin{aligned}
& \text { "You first give your child before you give (someone } \\
& \text { else's child). So you train these nurses or these health } \\
& \text { workers first... we need it more than these other areas } \\
& \text { that you go to... we are looking somewhere -for jobs. } \\
& \text { We have to create our jobs here first." }
\end{aligned}
$$

\section{DISCUSSION}

All stakeholders believed the most important building blocks to consider in the development of a sustainable healthcare facility in their community in Uganda are the establishment of strong, two-way partnerships. Such collaborations would maximize key deliverables such as education, higher standards of care, and maintainable infrastructure. Participants also reported potential unique obstacles including corruption and a shortage of skilled personnel, which must be recognized and considered as they are intertwined into each component and pose challenges to them all.

Examining how themes overlap also reveals various implications (Figure 2). Infrastructure can be considered both a building block and a deliverable, which highlights the importance of building on existing resources and institutions. This concept is in contrast to "re-inventing the wheel", which is a common pitfall of many well-meaning organizations. Proximity (having medical resources nearby) and personnel shortage are both building blocks and obstacles, which calls attention to the reality of scarce resources and the need for well-planned interventions that can address both issues. Finally, entitlement is listed as both a relationship and an obstacle. While stakeholders recognize the need for a higher standard of care, they still place a priority on employment opportunities being preferentially offered to people within the community, even if that individual is not the most qualified person for the job. Our framework reveals the complexity of relationships and the need to handle community expectations both delicately and directly to ensure future sustainability.

Our framework also provides a unique way of both identifying the most important components of building a sustainable health care facility in a resource-limited setting, and of characterizing the relationships between these components. The existing literature provides models of collaboration however none that describe a specific framework. But the fact that other authors have recognized similar components and concepts as ours provides some validation for their importance. ${ }^{21-24}$

One group that acknowledged similar components used a community engagement model to develop a partnership between a U.S. nursing school and the nursing community in the Caribbean, aimed at clinical, research and educational goals. ${ }^{23}$ Their model was based on the International Association for Public Participation's (IAP2) Spectrum of Public Participation, in which increasing levels of participation led to increasing public impact. ${ }^{24}$ The importance of working "directly with the public" to understand their priorities and to implement their solutions is in line with the major themes we identified in our study. ${ }^{24}$ However, our framework goes further by identifying forms of community participation that can pose obstacles to partnerships.

Limitations of the study include lack of generalizability of results to other communities, as many of the concepts described are specific to the culture of the region, and a potential sampling bias resulting from snowball sampling. However, this method has been considered the most effective by other authors given the history of mistrust of foreign organizations that exists in such rural communities. ${ }^{25}$ A small number of individuals were included in both the $\mathrm{MoH}$ and NGO leaders' groups due to lack of accessibility and time, however those who participated had the most indepth knowledge of local conditions and challenges. The fact that $100 \%$ of participants were interested in collaborating may have led to a response bias, although obstacles were still identified as one of the major themes. Researcher bias is another potential limitation; however, our stakeholder diversity, triangulation, member checking and use of two coders provides increased rigor in terms of added trustworthiness and reliability of the findings.

\section{CONCLUSIONS}

Our study provides the unique perspective of Ugandan stakeholders' beliefs on what is most important in the development of a sustainable health center by an NGO in their community. A recent editorial highlighted several components of building successful clinics in resource-limited settings like that of rural Uganda. ${ }^{7}$ The importance of developing relationships and recognizing potential obstacles are mirrored in our themes; however, this perspective originates from a U.S. academic institution. The local stakeholders' viewpoint as incorporated in our framework is critically valuable because the sustainability of the proposed clinic and other health-related interventions in such settings rely heavily on the capacities and motivation of the local community, not just the money and expertise of their Western partners. Through knowing what local partners really believe, we can foster true, bidirectional partnerships that can generate lasting health benefits for the communities that need it most.

\section{ACKNOWLEDGEMENTS}

The authors would like to thank the families, healthcare workers, and community leaders in Entebbe, as well as the Ugandan Ministry of Health and Cherish Uganda for sharing their thoughts, ideas, and concerns with us.

\section{ETHICS AND CONSENT}

The study protocol and consent procedures were approved by the Uganda National Council for Science and Technology and Baylor College of Medicine Institutional Review Board. All participants provided informed consent verbally with interpreters available if needed. 


\section{FUNDING}

There is no funding to report for this study.

\section{COMPETING INTERESTS}

The authors completed the Unified Competing Interest form at http://www.icmje.org/coi disclosure.pdf (available upon request from the corresponding author), and declare no conflicts of interest.

\section{CORRESPONDENCE TO:}

Carol C. Chen, MD

550 16th Street \#5151

San Francisco, CA 94143

USA

carol.chen@ucsf.edu 


\section{REFERENCES}

1. Kamiru HN, Ross MW, Bartholomew LK, McCurdy SA, Kline MW. Effectiveness of a training program to increase the capacity of health care providers to provide HIV/AIDS care and treatment in Swaziland. AIDS Care. 2009;21(11):1463-1470. doi:10.1080/0954 $\underline{0120902883093}$

2. Kawaza K, Machen HE, Brown J, et al. Efficacy of a low-cost bubble CPAP system in treatment of respiratory distress in a neonatal ward in Malawi. PLoS One. 2014;9(1):e86327. doi:10.1371/journal.pon e.0086327

3. Schutze GE, Ferris MG, Jones DC, et al. The Pediatric AIDS Corps: a 5-year evaluation. Pediatrics. 2014;133(6):e1548-e1554. doi:10.1542/peds.2013-293 $\underline{8}$

4. Crouse HL, Vaides H, Torres F, et al. Quality and effectiveness of a pediatric triage training program in a Guatemalan public hospital. Pediatr Emerg Care. 2016;32(8):525-528. doi:10.1097/pec.0000000000000 277

5. Plowfield LA, Wheeler EC, Raymond JE. Time, tact, talent, and trust: Essential ingredients of effective academic-community partnerships. Nurs Educ Perspect. 2005;26:217-220.

6. Heck JE, Bazemore A, Diller P. The Shoulder to Shoulder Model - Channeling medical volunteerism toward sustainable health change. Fam Med. 2007;39:644-650.

7. Collins EM. Developing health care clinic partnerships in resource-limited regions. Pediatrics. 2014;133(4):574-576. doi:10.1542/peds.2013-3946

8. The World Bank. Community-Driven Development Overview. Accessed January 5, 2018. http://www.worl dbank.org/en/topic/communitydrivendevelopment

9. Wandersman A. Community science: bridging the gap between science and practice with communitycentered models. Am J Community Psychol. 2003;31(3-4):227-242. doi:10.1023/a:1023954503247

10. Vancouver Coastal Health. Community engagement framework by Hariri N. Accessed January 5, 2018. http://www.vch.ca/get-involved/communityengagement

11. Bhawuk DPS, Mrazek S, Munusamy VP. From social engineering to community transformation: Amul, Grameen Bank, and Mondragon as exemplar organizations. Peace \& Policy. 2009;14. Accessed January 5, 2018. http://ssrn.com/abstract $=1483119$
12. Mansuri G, Rao V. Community-Based (and Driven) Development: A Critical Review. The World Bank; 2004. doi:10.1596/1813-9450-3209

13. Baird S, McIntosh C, Özler B. The Regressive Demands of Demand-Driven Development. The World Bank; 2011. doi:10.1596/1813-9450-5883

14. Wong S. What Have Been the Impacts of World Bank Community-Driven Development Programs? The World Bank; 2012.

15. Hasumi T, Jacobsen KH. Healthcare service problems reported in a national survey of South Africans. Int J Qual Health Care. 2014;26(4):482-489. doi:10.1093/intahc/mzu056

16. Ezzy D. Qualitative Analysis: Practice and Innovation. Routledge; 2002.

17. Shaghaghi A, Bhopal RS, Sheikh A. Approaches to recruiting 'hard-to-reach' populations into research: A review of the literature. Health Promot Perspect. 2011;1:86-94.

18. Braun V, Clarke V. Using thematic analysis in psychology. Qual Res Psychol. 2006;3(2):77-101. doi:1 $\underline{0.1191 / 1478088706 q p 0630 a}$

19. Denzin N, Lincoln Y. The Sage Handbook of Qualitative Research. 3rd ed. Sage; 2000.

20. Lincoln YS, Guba EG. Naturalistic Inquiry. Sage; 1985.

21. Lindau ST, Makelarski JA, Chin MH, Desautels S, Johnson D, Johnson WE. Building communityengaged health research and discovery infrastructure on the South Side of Chicago: Science in service to community priorities. Prev Med. 2011;52:200-227.

22. Kretzmann J, McKnight JP. Assets-based community development. Natl Civic Rev. 1996;85(4):23-29. doi:10.1002/ncr.4100850405

23. Powell DL, Gilliss CL, Hewitt HH, Flint EP. Application of a partnership model for transformative and sustainable international development. Public Health Nurs. 2010;27(1):54-70. doi:10.1111/j.1525-14 46.2009.00827.x

24. IAP2 Spectrum of Public Participation, International Association for Public Participation. Published 2007. Accessed January 5, 2018. http://iap2 canada.ca/page-1020549 
25. Foley SM, Raphael R, Adolphe M, et al. Haitian, Chinese, Somali, Ethiopian, and Asian/Pacific Islander Perspectives on Research. Pediatrics.

2010;126:S137-S142. doi:10.1542/peds.2010-1466g 